\title{
Cost analysis of air capture driven by wind energy under different scenarios
}

\author{
Yinghui GENG ${ }^{1}$, Canbing $\mathrm{LI}^{1}$ (D), Yijia $\mathrm{CAO}^{1}$, Hao $\mathrm{CHEN}^{2}$, \\ Yonghong KUANG ${ }^{1}$, Xuedong REN $^{1}$, Xinwei BAI ${ }^{1}$
}

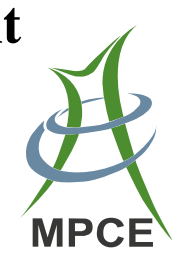

\begin{abstract}
Reducing the concentration of carbon dioxide $\left(\mathrm{CO}_{2}\right)$ in the air can effectively alleviate climate change. Air capture, which captures $\mathrm{CO}_{2}$ directly from the air in an industrial process, is an alternative option to address climate change. The results of recent studies on the energy demand in $\mathrm{CO}_{2}$ capture process and the costs of $\mathrm{CO}_{2}$ transport and $\mathrm{CO}_{2}$ storage in air capture are analyzed in this paper. Considering renewable energy will not produce additional $\mathrm{CO}_{2}$ in the process of utilization, the electric energy in $\mathrm{CO}_{2}$ capture process of air capture driven by wind energy is different from that of carbon capture and storage. Taking externalities of renewable energy into
\end{abstract}

CrossCheck date: 14 April 2015

Received: 30 November 2014/Accepted: 14 April 2015/Published online: 11 September 2015

(C) The Author(s) 2015. This article is published with open access at Springerlink.com

$\triangle$ Canbing LI

licanbing@gmail.com; licanbing@qq.com

Yinghui GENG

861450466@qq.com

Yijia CAO

yjcao@hnu.edu.cn

Hao CHEN

haochen@aimlab.org

Yonghong KUANG

117394099@qq.com

Xuedong REN

980560600@qq.com

Xinwei BAI

784662753@qq.com

1 College of Electrical and Information Engineering, Hunan University, Changsha 410082, China

2 College of Computer Science and Electronic Engineering, Hunan University, Changsha 410082, China account, the trading price of $\mathrm{CO}_{2}$ emission is taken to assess the cost of electric energy in $\mathrm{CO}_{2}$ capture of air capture driven by wind energy. Finally, the total cost and the total cost savings of air capture driven by wind energy under different scenarios are analyzed.

Keywords $\mathrm{CO}_{2}$ capture and storage, Renewable energy, Wind power, Air capture, $\mathrm{CO}_{2}$ emission

\section{Introduction}

Burning large amounts of fossil fuels releases $\mathrm{CO}_{2}$ to air, which is the main cause of greenhouse effect. Some literatures pointed out that the global temperature will probably increase $2{ }^{\circ} \mathrm{C}$ compared with the pre-industrial level due to greenhouse gas emissions by 2050 [1-3]. And the possibility that the global temperature would increase 2 ${ }^{\circ} \mathrm{C}$ will be as high as $75 \%$ if $\mathrm{CO}_{2}$ emissions are not less than 50 Gt by 2020 [1]. Controlling greenhouse gas emissions becomes one of the most challenging environmental problems that the world is facing [4].

Carbon capture and storage (CCS), as a potential method to address climate change, is gaining widespread interest all over the world. CCS can handle $85 \% \sim 95 \%$ of $\mathrm{CO}_{2}$ in the exhaust gases produced by coal-fired power plants and other industrial enterprises [5]. The International Energy Agency (IEA) predicted that if CCS could capture, transport, and store more than $8 \mathrm{Gt}$ of $\mathrm{CO}_{2}$ every year, $19 \%$ of global $\mathrm{CO}_{2}$ emissions would be reduced by 2050 [5, $6]$.

With the rapidly rising concentration of $\mathrm{CO}_{2}$ in the air, which has reached approximately $400 \mathrm{ppm}$, air capture has also attracted wide attention. Air capture, with its installation site unlimited to large stationary sources, can capture 
$\mathrm{CO}_{2}$ from the mobile sources [7-9]. Even relatively unsafe $\mathrm{CO}_{2}$ storage, for example, the storage capacity is $1 \%$ reduction of the $\mathrm{CO}_{2}$ in the air per 1000 years, can help to mitigate medium-term climate change at least $[5,10,11]$. Air capture driven by fossil fuels, however, consumes plenty of energy and produces additional $\mathrm{CO}_{2}$.

Current economic analysis on $\mathrm{CO}_{2}$ capture system has been conducted by many researchers, but they usually study the system driven by electricity or conventional energy [12]. Air capture driven by renewable energy has the potential to avoid dangerous climate change. Renewable energy, such as wind and solar energy, has the characteristics of cleanness and huge development potential, without producing additional $\mathrm{CO}_{2}$ in the process of utilization. It is possible for carbon capture device to function normally when it is only powered by intermittent sources. Researchers have demonstrated that concentrated solar energy is a viable energy source to provide high temperature process heat. $\mathrm{CO}_{2}$ capture from air powered by concentrated solar was proposed to supply the thermal energy $[13,14]$. Co-location of air capture system powered by wind energy is proposed and it can capture approximately $75 \mathrm{Mt}$ of $\mathrm{CO}_{2}$ every year in Kerguelen plateau, a remote ocean site with steady wind resources [15]. The brief technical details of air capture driven by renewable energy are as follows:

1) Air capture devices driven by renewable energy can be regarded as a simple load, and it can work like microgrid dispatching load.

2) Air capture devices consume a large part of energy in the form of heat and heat energy can keep constant temperature within minutes. So carbon capture devices, to a certain extent, can function normally when it is only powered by intermittent sources.

3) Energy analysis on $\mathrm{CO}_{2}$ capture from air systems is performed [16, 17]. $\mathrm{CO}_{2}$ capture from air system is composed of contactor, causticizer, slaker, calciner, kiln, and compressor. The energy requirements, energy types, acceptable active power fluctuation rate for each device are different, and it could not work normally within the acceptable lower and upper limits. Air capture driven by renewable energy has attracted attention, but its feasibility is only studied from technical view, not from economic view.

Our primary goal in this paper is to present an approach to reduce the cost of air capture devices in a feasible manner. In this paper, the energy demand in $\mathrm{CO}_{2}$ capture process and the costs of $\mathrm{CO}_{2}$ transport and $\mathrm{CO}_{2}$ storage in air capture driven by wind energy are analyzed. Then, four scenarios of air capture driven by wind energy are proposed, and the cost and the cost savings of each process are calculated under each scenario.

\section{Cost analysis of each stage in air capture driven by wind energy}

The process of air capture driven by wind energy includes $\mathrm{CO}_{2}$ capture, $\mathrm{CO}_{2}$ transportation and $\mathrm{CO}_{2}$ storage. And the function of wind energy driven air capture system is shown in Fig. 1, which reflects each cost component involved in the paper.

\section{1 $\mathrm{CO}_{2}$ capture}

The main advantage of air capture driven by wind power is that it can capture $\mathrm{CO}_{2}$ without producing additional $\mathrm{CO}_{2}$. Comparing the equal power generation of fossil fuel with wind energy, wind power releases almost zero $\mathrm{CO}_{2}$ emission to the environment. Externalities of renewable energy should be taken into consideration when evaluating the cost of electric energy in $\mathrm{CO}_{2}$ capture process.

\subsubsection{Cost proportion in onshore and offshore wind farms}

The cost of wind power is mainly determined by investment cost, operation and maintenance cost, turbine lifetime, and discount rate. The cost percentage of each part in onshore and offshore wind power projects is shown in Table 1 [18]. If the grid-connection cost can be saved, air capture driven by wind energy could reduce the cost of wind power.

These data statistics are from onshore and offshore wind power projects in developed countries in 2011. Air capture devices driven by wind energy have the following advantages: (1) Carbon capture devices are kind of flexible load, which can to some extent utilize intermittent energy sources such as wind energy and solar energy; (2) Wind power will bring power grid operation management and

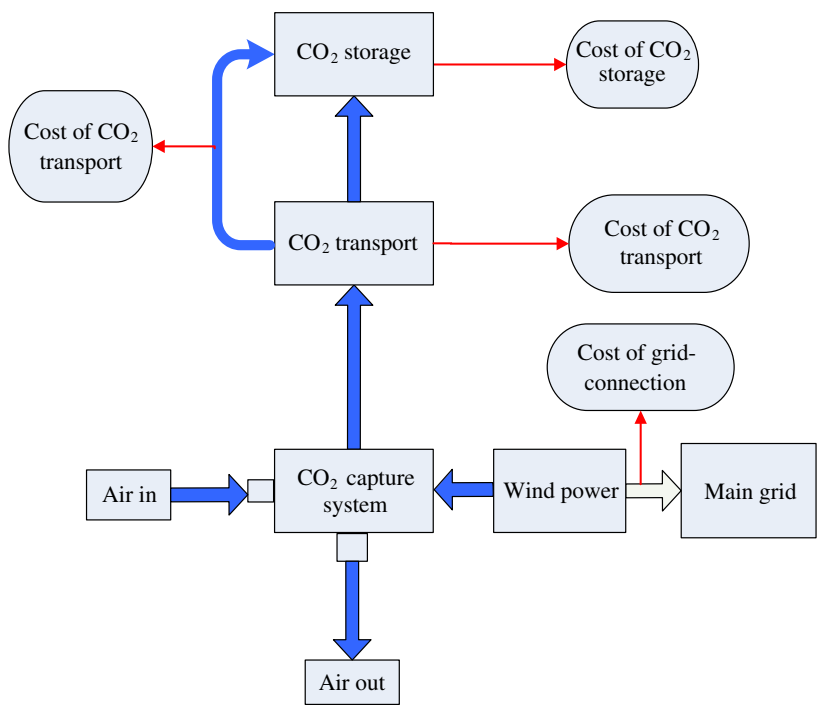

Fig. 1 Function of wind energy driven air capture system 
Table 1 Cost proportion of each part in onshore and offshore wind farms

\begin{tabular}{lll}
\hline Parameters & Onshore & Offshore \\
\hline Capital investment costs $(\$ / \mathrm{kW})$ & $1700 \sim 2450$ & $3300 \sim 5000$ \\
Wind turbine cost share $(\%)$ & $65 \sim 84$ & $30 \sim 50$ \\
Grid connection cost share $(\%)$ & $9 \sim 14$ & $15 \sim 30$ \\
Construction cost share $(\%)$ & $4 \sim 16$ & $15 \sim 25$ \\
Other capital cost share $(\%)$ & $4 \sim 10$ & $8 \sim 30$ \\
\hline
\end{tabular}

scheduling an unprecedented uncertainty when connected to the grid due to its intermittency and volatility [19]. Wind electricity can be fully used to capture $\mathrm{CO}_{2}$ if air capture devices are driven by wind power, so it can avoid curtailed electric energy. Curtailed electric energy means large amounts of electricity from renewable sources are wasted due to the real-time balance between generation and load.

\subsubsection{Direct cost of wind power generation-onshore}

The direct cost of wind power generation is calculated based on life cycle cost analysis, which equally divides the whole expense of wind power generation over the whole life cycle. In this paper, the direct cost of wind energy is roughly estimated without considering the loan and interest. It is mainly determined by the following parameters $[18,20]$ :

1) Capital cost. It includes wind turbines cost, foundations cost, road construction cost, and grid-connection cost, accounting for $80 \%$ of the overall cost of wind power project.

2) $O \& M$ cost. Although the $O \& M$ cost is not clearly defined, it consists of material cost, equipment operation and maintenance cost, wages, and rent in most cases.

3) Life cycle of wind power project.

As wind power does not need fuel, which is the basic difference between fossil fuel generation and wind power, there is no need to consider the fuel cost in this paper. In the meantime, air capture devices driven by wind energy can save the cost of grid-connection, so the total investment cost can be calculated by

$C_{Z}=C_{C}+C_{O \& M}-C_{G}$

where $C_{Z}$ is the total investment cost; $C_{C}$ is the capital cost of wind farms; $C_{O \& M}$ is the O\&M cost; $C_{G}$ is the cost of grid-connection.

The unit cost of wind farm investment is equal to the wind power investment cost per $\mathrm{kWh}$, which can be expressed as follows:

$C_{D}=\frac{C_{C}+C_{O \& M}-C_{G}}{Q}$ where $C_{D}$ is the unit cost of wind farm investment; $Q$ is the cumulative electrical production and it can be formulated as follows:

$Q=N Q_{i}$

where $N$ is the lifetime of wind turbine; $Q_{i}$ is the electrical generating capacity per year, which can be expressed as follows:

$Q_{i}=T P_{n}$

where $P_{n}$ is the wind turbine capacity; $T$ is the full load hours for onshore installations.

The direct cost of wind power generation is estimated based on the following data $[18,20]$. At the moment the average size of wind turbine ranges from $2 \mathrm{MW}$ and $3 \mathrm{MW}$, with $2 \mathrm{MW}$ selected in this paper; the lifetime of wind turbine is 20 years; the capital cost of wind farm is $\$ 760 \sim 970 / \mathrm{kW}$; the O\&M cost is approximately $\$ 10 / \mathrm{MW}$ $\mathrm{h}$ in the $2000 \mathrm{~s}$; the cost of grid-connection is about $\$ 115.24 / \mathrm{kW}$; the average number of full load hours for onshore wind installations is between 1700 and 3000 hours/ year, with 2000 hours/year selected in this paper. Thus, when wind farms are not connected to the grid, the direct cost of wind power generation is in the range of 2.61 3.14 cents/kWh using (1) (4). If when wind farms are connected to the grid, the range of direct cost of wind power generation is $3.10 \sim 6$ cents/kWh using the data from [20].

\subsubsection{External cost of wind power generation}

The externalities of wind energy should be taken into account to evaluate the external cost of wind energy. External cost is the cost of the impact coming from the environment because of the pollutants emitted from the specified technology [21]. Coal-fired power plants release $\mathrm{CO}_{2}$ emissions into the air. However, Wind power generation almost release no $\mathrm{CO}_{2}$ emissions. In other words, wind power generation for one $\mathrm{kWh}$ can reduce $\mathrm{CO}_{2}$ emissions of equal amount $\mathrm{kWh}$ from coal-fired power plants. Thus, the external cost of wind power generation can be calculated by:

$C_{W}=P_{W} Q_{W}$

where $C_{W}$ is the external cost of wind power generation; $P_{W}$ is the charge standard for $\mathrm{CO}_{2}$ emissions per $\mathrm{kg} ; Q_{W}$ is the $\mathrm{CO}_{2}$ emission reduction by wind power generation per $\mathrm{kWh}$.

The value of $\mathrm{CO}_{2}$ external cost is $\$ 0.018 / \mathrm{kg}$, and coalfired power plants release $\mathrm{CO}_{2} 0.86 \sim 1.29 \mathrm{~kg} / \mathrm{kWh}[21$, 22], so wind power generation for $1 \mathrm{kWh}$ can reduce equal amount of $\mathrm{CO}_{2}$ emissions into the air. Thus, the external cost of wind power generation ranges from 1.55 to 2.32 cents/kWh based on (5). 


\subsubsection{Electricity consumption in $\mathrm{CO}_{2}$ capture stage}

Carbon capture devices consume large amounts of electricity $\mathrm{CO}_{2}$ capture process. For example, the electricity consumption of CCS follows a downward trend, with $306 \mathrm{kWh} / \mathrm{t}$ of $\mathrm{CO}_{2}$ in 2005 and $196 \mathrm{~kW} \mathrm{h/t} \mathrm{CO}_{2}$ after 2014, according to the IEA Greenhouse Gas R\&D Programme (IEA GHG) [23]. However, if $\mathrm{CO}_{2}$ is captured directly from air, more energy is needed. Air capture can be driven by natural gas, solar, wind, and other energy. And the energy requirements of air capture driven by different energy range from $110 \mathrm{~kJ} / \mathrm{mole} \mathrm{CO}_{2}$ when 2nd-Law Efficiency is $50 \%$ to 2485 thermal $\mathrm{kJ} / \mathrm{mol} \mathrm{CO}$ when 2 nd-Law Efficiency is $2.4 \%$, driven by solar energy [24]. The energy requirement of air capture driven by wind energy is 442 $\mathrm{kJ} / \mathrm{mol} \mathrm{CO}_{2}$, which equals to $2790 \mathrm{kWh} / \mathrm{t}$ of $\mathrm{CO}_{2}$ [25].

\subsubsection{Cost of electric energy in $\mathrm{CO}_{2}$ capture process}

The cost of electric energy needed to capture per ton $\mathrm{CO}_{2}$ can be calculated as follows:

$C_{S}=C_{\mathrm{e}} e$

where $C_{S}$ is the cost of electric energy, which air capture needs to capture per ton of $\mathrm{CO}_{2} ; C_{\mathrm{e}}$ is the social cost of wind energy per $\mathrm{kWh}$; $e$ is the electric energy which air capture needs to capture per ton of $\mathrm{CO}_{2}$. Social cost of carbon, as defined by [26], is the monetary value of world-wide damage done by emitting one more ton of carbon. It is the difference between the direct cost and the external cost.

The social cost of wind energy is the difference between the direct cost and the external cost of wind power generation. Thus, the value of social cost of wind energy has the following two scopes: when wind farms are not connected to the grid, the cost is $0.84 \sim 1.06$ cents $/ \mathrm{kWh}$; and $1.55 \sim 3.68$ cents/kWh when wind farms are connected to the grid. In $\mathrm{CO}_{2}$ capture process, $2790 \mathrm{kWh}$ of electric energy is needed to capture per ton of $\mathrm{CO}_{2}$. Thereby, the cost of electric energy needed to capture per ton of $\mathrm{CO}_{2}$ under the two situations are obtained using (6). When wind farms are not connected to grid, the cost of electric energy is $\$ 23.44 \sim 29.57 / \mathrm{t}$ of $\mathrm{CO}_{2}$ and $\$ 43.25 \sim 102.7 / \mathrm{t}$ of $\mathrm{CO}_{2}$ when wind farms are connected to grid. The corresponding increase of the cost is $\$ 43.25 / \mathrm{t}$ to $\$ 64.73 / \mathrm{t}$ of $\mathrm{CO}_{2}$, respectively, without considering the externalities wind energy.

\section{$2.2 \mathrm{CO}_{2}$ transport}

Large amounts of $\mathrm{CO}_{2}$ captured by air capture devices need to be transported to the storage site, and pipeline transport is the most economic transportation method for onshore air capture [26]. The cost of pipeline transport is mainly determined by the physical and social terrain that the pipelines go through, the characteristic of pipeline, and the number of booster stations. Taking the environment and safety factor into consideration, pipe is usually buried underground for a relatively stable temperature [26]. For a $500 \mathrm{MW}$ gas fired combined cycle power station, it costs 6 dollars to transport per ton of $\mathrm{CO}_{2}$ [27].

\section{$2.3 \mathrm{CO}_{2}$ storage}

There are some geologic $\mathrm{CO}_{2}$ storage methods: depleted gas/oil reservoir, saline aquifer storage, ocean storage via pipeline, ocean storage via tanker [28]. The cost of each $\mathrm{CO}_{2}$ storage method is shown in Table 2 .

The cost range of $\mathrm{CO}_{2}$ storage is $\$ 2 \sim 15 / \mathrm{t} \quad \mathrm{CO}_{2}$ excluding the most expensive ocean tanker method [28].

\section{Cost analysis of air capture driven by wind energy under different scenarios}

\subsection{Scenario analysis of air capture driven by wind energy}

CCS is usually installed around large stationary sources such as power plants and other enterprises. The installation site of air capture is less restrictive. Therefore, air capture can be installed in $\mathrm{CO}_{2}$ storage sites, which will save transportation cost. It will save the cost of grid-connection if wind farms are not connected to the grid. Thus, in this section, four scenarios are proposed to reduce the costs of air capture driven by wind energy in Table 3 .

Table 2 Cost of $\mathrm{CO}_{2}$ storage with different methods

\begin{tabular}{lclc}
\hline Methods & $\begin{array}{c}\text { Base cost } \\
\left(\$ / \mathrm{tCO}_{2}\right)\end{array}$ & $\begin{array}{l}\text { High cost } \\
\left(\$ / \mathrm{t} \mathrm{CO}_{2}\right)\end{array}$ & $\begin{array}{r}\text { Low cost } \\
\left(\$ / \mathrm{CO}_{2}\right)\end{array}$ \\
\hline Depleted gas reservoir & 4.87 & 19.43 & 1.20 \\
Depleted oil reservoir & 3.82 & 11.16 & 1.21 \\
Deep saline aquifer & 2.93 & 11.71 & 1.14 \\
Ocean storage via pipeline & 5.53 & 14.23 & 2.90 \\
Ocean storage via tanker & 17.64 & 22.79 & 15.76 \\
\hline
\end{tabular}

Table 3 Definition of four scenarios

\begin{tabular}{lll}
\hline Scenario & Cost of grid-connection & Cost of $\mathrm{CO}_{2}$ transport \\
\hline I & $\sqrt{ }$ & $\sqrt{ }$ \\
II & $\sqrt{ }$ & $\triangle$ \\
III & $\triangle$ & $\sqrt{ }$ \\
IV & Generating cost is 0 & $\triangle$ \\
\hline
\end{tabular}

" $\triangle$ " represents the grid-connection cost or the $\mathrm{CO}_{2}$ storage cost cannot be saved; " $\sqrt{ }$ " represents the grid-connection cost or the $\mathrm{CO}_{2}$ transport cost can be saved 
Scenario I: When air capture devices driven by wind energy are installed in the sites suitable for $\mathrm{CO}_{2}$ storage, and wind farms are not connected to grid, the costs of gridconnection and $\mathrm{CO}_{2}$ transport can be saved.

Scenario II: When air capture devices driven by wind energy are installed in the sites unsuitable for $\mathrm{CO}_{2}$ storage, and wind farms are not connected to grid, only the cost of $\mathrm{CO}_{2}$ grid-connection can be saved.

Scenario III: When air capture devices driven by wind energy are installed in the sites suitable for $\mathrm{CO}_{2}$ storage, and wind farms are connected to grid, only the cost of $\mathrm{CO}_{2}$ transport can be saved.

Scenario IV: When wind farms are connected to grid, the cost of electric energy is $\$ 43.25 \sim 102.7 / t \mathrm{CO}_{2}$. Air capture devices driven by wind energy can utilize curtailed electric energy. Thus, in $\mathrm{CO}_{2}$ capture process, the cost of electric energy is 0 and the cost of $\$ 43.25 \sim 102.7 / \mathrm{t} \mathrm{CO}_{2}$ can be saved. When air capture devices driven by wind energy are installed in the sites unsuitable for $\mathrm{CO}_{2}$ storage, the costs of $\mathrm{CO}_{2}$ transport and $\mathrm{CO}_{2}$ storage are still needed.

\subsection{Cost prediction of air capture}

At present, air capture is still in its initial stage.

Although it is technologically feasible, the economic feasibility in large-scale still needs to be further explored for air capture to play an important role in $\mathrm{CO}_{2}$ capture in the future [7, 29]. The predictable cost of air capture varies tremendous and is in the range of $\$ 30 \sim 1000 / t$ of $\mathrm{CO}_{2}$ [7]. The American Physical Society (APS) estimates that the cost of air capture is nearly $\$ 600 / t$ of $\mathrm{CO}_{2}[31]$ and there is a high possibility that the cost will be much more than $\$ 100 / t$ of $\mathrm{CO}_{2}$ [30]. In the coming decades, air capture could plausibly achieve $\$ 200 / \mathrm{t}$ of $\mathrm{CO}_{2}$ to $\$ 500 / \mathrm{t}$ of $\mathrm{CO}_{2}$ [8]. If the cost of air capture is less than $\$ 50 / t$ of $\mathrm{CO}_{2}$, it will be more competitive among climate mitigation technologies.

\subsection{Cost of air capture driven by wind energy under four different scenarios}

In this paper, the total cost of air capture is $\$ 600 / t$ of $\mathrm{CO}_{2}$ according to the data in $[29,30]$. The total cost and the cost savings of air capture driven wind energy are shown in Table 4 and Table 5 based on whether considering the

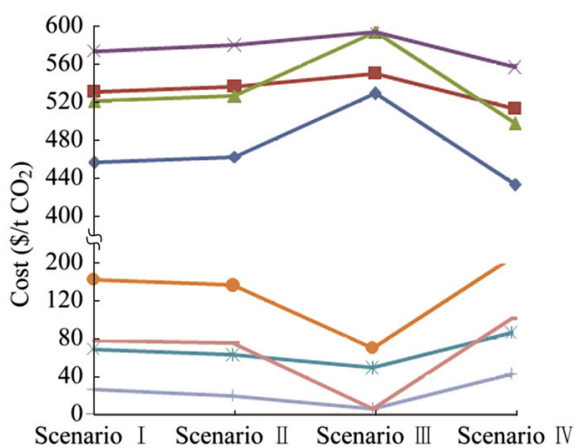

$$
\begin{aligned}
& \rightarrow \text { Mininum total cost with considering externality of wind energy } \\
& \rightarrow-\text { Maxinum total cost with considering externality of wind energy } \\
& \rightarrow-\text { Maxinum total cost without considering externality of wind energy } \\
& \rightarrow-\text { Mininum total cost without considering externality of wind energy } \\
& \rightarrow-\text { Maxinum total cost with considering externality of wind energy } \\
& - \text { Mininum total cost savings without considering externality of wind energy } \\
& - \text { Maxinum total cost savings without considering externality of wind energy }
\end{aligned}
$$

\begin{tabular}{|c|c|c|c|c|c|c|}
\hline Scenario & $\begin{array}{l}\text { External cost of wind power } \\
\text { generation }\end{array}$ & $\begin{array}{l}\text { Cost of grid- } \\
\text { connection }\end{array}$ & $\begin{array}{l}\text { Cost of } \mathrm{CO}_{2} \\
\text { transport }\end{array}$ & $\begin{array}{l}\text { Cost of } \mathrm{CO}_{2} \\
\text { storage }\end{array}$ & $\begin{array}{l}\text { Total cost } \\
\text { savings }\end{array}$ & Total cost \\
\hline I & $43.25 \sim 64.73$ & $19.81 \sim 73.13$ & 6 & $x$ & $69.06 \sim 143.86$ & $456.14 \sim 530.94$ \\
\hline II & $43.25 \sim 64.73$ & $19.81 \sim 3.13$ & $x$ & $x$ & $63.06 \sim 137.86$ & $462.14 \sim 536.94$ \\
\hline III & $43.25 \sim 64.73$ & $x$ & 6 & $\times$ & $49.25 \sim 70.73$ & $529.27 \sim 550.75$ \\
\hline IV & $43.25 \sim 64.73$ & $43.25 \sim 102.7$ & $x$ & $x$ & $86.5 \sim 167.43$ & $432.57 \sim 513.5$ \\
\hline
\end{tabular}

Fig. 2 Results of four scenarios

Table 4 Total cost and cost savings of air capture driven wind energy considering externality of wind energy $\left(\$ / t \mathrm{CO}_{2}\right)$

Table 5 Total cost and cost savings of air capture driven wind energy without considering externality of wind energy $\left(\$ / t \mathrm{CO}_{2}\right)$

\begin{tabular}{lllllc}
\hline Scenario & $\begin{array}{l}\text { External cost of wind power } \\
\text { generation }\end{array}$ & $\begin{array}{l}\text { Cost of grid- } \\
\text { connection }\end{array}$ & $\begin{array}{l}\text { Cost of } \mathrm{CO}_{2} \\
\text { transport }\end{array}$ & $\begin{array}{l}\text { Cost of } \mathrm{CO}_{2} \\
\text { storage }\end{array}$ & $\begin{array}{l}\text { Total cost } \\
\text { savings }\end{array}$ \\
\hline I & $\times$ & $19.81 \sim 73.13$ & 6 & $\times$ & $25.81 \sim 79.13$ \\
II & $\times$ & $19.81 \sim 73.13$ & $\times$ & $\times$ & $520.87 \sim 574.19$ \\
III & $\times$ & $\times$ & 6 & $\times$ & $6.81 \sim 73.13$ \\
IV & $\times$ & $43.25 \sim 102.7$ & $\times$ & $\times$ & $526.87 \sim 580.19$ \\
\hline
\end{tabular}


externalities of wind or not and the above analysis under four scenarios.

Each value in the table represents the cost saving or total cost under different scenarios, and " $x$ " represents the cost that cannot be saved.

Finally, the results of four scenarios are shown in Fig. 2 to visually compare the differences in the total cost and the cost savings of each scenario.

\section{Conclusion}

Air capture, as a mitigation technology, has the potential to stabilize and reduce greenhouse gas emissions. Wind energy, without producing additional $\mathrm{CO}_{2}$ in the process of utilization, can drive air capture to capture $\mathrm{CO}_{2}$ to reduce the concentration of $\mathrm{CO}_{2}$ in the air. Taking externalities of renewable energy into account, the total cost and the total cost savings of air capture driven by wind energy are calculated under four scenarios in this paper. With the previous different scenarios, the following conclusions are:

1) Considering externality of wind energy, Scenario IV is the most cost-effective. It could save $\$ 86.5 \sim 167.43 / \mathrm{t}$ $\mathrm{CO}_{2}$, which accounts for $20 \% \sim 32.1 \%$ of the total cost.

2) Without considering externality of wind energy, Scenario III saves the least cost, which saves $\$ 6 / t$ $\mathrm{CO}_{2}$.

Scenario IV considering externality of wind energy costs the least, so it should be developed and applied preferentially.

At present, the cost of air capture is still very high. Its cost may decline with a lower price of renewable energy sources, the optimization design and scheduling of $\mathrm{CO}_{2}$ capture devices.

Acknowledgment This work was supported by the International Science \& Technology Cooperation Program of China (No. 2012DFA70580).

Open Access This article is distributed under the terms of the Creative Commons Attribution 4.0 International License (http:// creativecommons.org/licenses/by/4.0/), which permits unrestricted use, distribution, and reproduction in any medium, provided you give appropriate credit to the original author(s) and the source, provide a link to the Creative Commons license, and indicate if changes were made.

\section{References}

[1] Meinshausen M, Meinshausen N, Hare W et al (2009) Greenhouse-gas emission targets for limiting global warming to $2{ }^{\circ} \mathrm{C}$. Nature 458(7242): 1158-1162

[2] Elzen MD, Höhne N (2010) Sharing the reduction effort to limit global warming to $2{ }^{\circ} \mathrm{C}$. Clim Policy 10(3):247-260
[3] Meinshausen $\mathrm{M}$ (2005) On the risk of overshooting $2{ }^{\circ} \mathrm{C}$. In: Avoiding dangerous climate change: proceedings of the international symposium on the stabilisation of greenhouse gas concentrations, Exeter, UK, 1-3 Feb 2005, 6 pp

[4] Rao AB, Rubin ES (2002) A technical, economic, and environmental assessment of amine-based $\mathrm{CO}_{2}$ capture technology for power plant greenhouse gas control. Environ Sci Technol 36(20):4467-4475

[5] Scott V, Gilfillan S, Markusson N et al (2013) Last chance for carbon capture and storage. Nat Clim Change 3(2):105-111

[6] World energy outlook 2011 (2011) International Energy Agency, Paris, France

[7] Lackner KS, Brennan S, Matter JM et al (2012) The urgency of the development of $\mathrm{CO}_{2}$ capture from ambient air. Proc Natl Acad Sci USA 109(33):13156-13162

[8] Keith DW, Ha-Duong M, Stolaroff JK (2006) Climate strategy with $\mathrm{CO}_{2}$ capture from the air. Clim Change 74(1/2/3):17-45

[9] Li CB, Wang H, Geng YH et al (2014) The key technologies of using renewable energy to capture carbon from ambient air directly. Autom Electr Power Syst 38(17):130-136. doi:10.7500/ AEPS20140521008 (in Chinese)

[10] Stone EJ, Lowe JA, Shine KP (2009) The impact of carbon capture and storage on climate. Energy Environ Sci 2(1):81-91

[11] Gerlagh R, van der Zwaan B (2011) Evaluating uncertain $\mathrm{CO}_{2}$ abatement over the very long term. Environ Model Assess 17(1/ 2):137-148

[12] Davison J (2007) Performance and costs of power plants with capture and storage of $\mathrm{CO}_{2}$. Energy 32(7):1163-1176

[13] Nikulshina V, Hirsch D, Mazzotti M et al (2006) $\mathrm{CO}_{2}$ capture from air and co-production of $\mathrm{H}_{2}$ via the $\mathrm{Ca}(\mathrm{OH})_{2}-\mathrm{CaCO}_{3}$ cycle using concentrated solar power-thermodynamic analysis. Energy 31(12):1715-1725

[14] Nikulshina V, Steinfeld A (2009) $\mathrm{CO}_{2}$ capture from air via $\mathrm{CaO}$ carbonation using a solar-driven fluidized bed reactor-effect of temperature and water vapor concentration. Chem Eng J 155(3):867-873

[15] Goldberg DS, Lackner KS, Han P et al (2013) Co-location of air capture, subseafloor $\mathrm{CO}_{2}$ sequestration, and energy production on the Kerguelen Plateau. Environ Sci Technol 47(13):75217529

[16] House KZ, Baclig AC, Ranjan M et al (2011) Economic and energetic analysis of capturing $\mathrm{CO}_{2}$ from ambient air. Proc Natl Acad Sci USA 108(51):20428-20433

[17] Baciocchi R, Storti G, Mazzotti M (2006) Process design and energy requirements for the capture of carbon dioxide from air. Chem Eng Process 45(12):1047-1058

[18] Renewable energy technologies: cost analysis series. International Renewable Energy Agency (IRENA), Abu Dhabi, 2012

[19] Wang J, Botterud A, Bessa R et al (2011) Wind power forecasting uncertainty and unit commitment. Appl Energy 88(11): 4014-4023

[20] Blanco MI (2009) The economics of wind energy. Renew Sustain Energy Rev 13(6/7):1372-1382

[21] El-Kordy MN, Badr MA, Abed KA et al (2002) Economical evaluation of electricity generation considering externalities. Renew Energy 25(2):317-328

[22] Şahin AD (2004) Progress and recent trends in wind energy. Prog Energy Combust Sci 30(5):501-543

[23] Li CB, Shi HQ, Cao YJ et al (2015) Comprehensive review of renewable energy curtailment and avoidance: a specific example in China. Renew Sustain Energy Rev 41:1067-1079

[24] House KZ, Baclig AC, Ranjan M et al (2011) Supplementary information for economic and energy analysis of capturing $\mathrm{CO}_{2}$ from the air. http://www.pnas.org/content/suppl/2011/12/01/ 1012253108.DCSupplemental/Appendix.pdf. Accessed 20 Dec 2011 
[25] Zeman F (2007) Energy and material balance of $\mathrm{CO}_{2}$ capture from the ambient air. Environ Sci Technol 41(21):7558-7563

[26] Pearce DW (2003) The social cost of carbon and its policy implications. Oxf Rev Econ Policy 19(3):362-384

[27] Gale J, Davison J (2004) Transmission of $\mathrm{CO}_{2}$-safety and economic considerations. Energy 29(9/10):1319-1328

[28] Heddle G, Herzog $\mathrm{H}$, Klett $\mathrm{M}$ (2003) The economics of $\mathrm{CO}_{2}$ storage. MIT LFEE 2003-003 RP, MIT Lab for Energy and the Environment Publication, Cambridge

[29] Socolow R, Desmond M, Aines R et al (2011) Direct air capture of $\mathrm{CO}_{2}$ with chemicals: a technology assessment for the APS panel on public affairs. American Physical Society, Washington, DC

[30] Keith DW (2009) Why capture $\mathrm{CO}_{2}$ from the atmosphere? Science 325(5948):1654-1655

Yinghui GENG received the B. Eng degree from Northwest University for Nationalities in 2013. Now she is pursuing her master degree in Hunan University. Her research interest is power system dispatching.

Canbing LI received $\mathrm{B}$. Eng and $\mathrm{PhD}$ degrees in Electrical Engineering from Tsinghua University in 2001 and 2006 respectively. Currently, he is a professor of Hunan University. His research interests include smart grid and energy sustainability.

Yijia CAO received $\mathrm{PhD}$ degree from Huazhong University of Science and Technology in 1994. He became a special-term professor of the "Cheung Kong Scholars Program" in Zhejiang University in 2001. Since March 2008, he has been serving as Vice President of
Hunan University. His research interests include power system cascading failure, power system information technology, computational intelligence and its applications to smart grid optimal operation.

Hao CHEN received the BS degree from Sichuan University in 1998, and the $\mathrm{PhD}$ degree from Huazhong University of Science and Technology in 2005. He is now an associate Professor of Hunan University, China. His research interests include parallel and distributed computing, operating systems, cloud computing and systems security.

Yonghong KUANG received the BS degree and Master degree in 2003 and 2007 respectively. She is a lecturer of Hunan Institute of Engineering. She is also working toward the $\mathrm{PhD}$ degree in Hunan University. Her research interest is optimal scheduling of micro grid.

Xuedong REN received the B. Eng degree from Shandong Agricultural University in 2014. Now he is pursuing his master degree in Hunan University. His research interest is power system dispatching.

Xinwei BAI received the B. Eng degree from Hunan University in 2014. Now, he is pursuing master degree in Hunan University. His research interest includes power system dispatching. 